\title{
Change in the Attitude and Expectations of Dental Students Regarding Aging by Introduction of a Geriatric Education Program: A Mixed Method Study
}

\section{Pragati Kaurani*, Ajay Gupta and Bhavya Nigam}

Department of Prosthodontics, Mahatma Gandhi Dental College and Hospital, India

*Corresponding Author: Pragati Kaurani, Department of Prosthodontics, Mahatma Gandhi Dental College and Hospital, India. Email: drpragatikaurani@rediffmail.com DOI: $10.31080 /$ ASDS.2021.05.1099
Received: March 16, 2021

Published: April 16, 2021

(c) All rights are reserved by Pragati Kaurani., et al.

\begin{abstract}
Introduction: India's growing aging population poses greater challenges for the dental clinicians. Undergraduate dental education programs must include geriatric dental education to train students to meet these challenges. Dental colleges in India, currently do not provide a formal geriatric dental education. Introduction of a structured educational intervention can bring about a change in the attitudes and expectations of students regarding the aging, which in turn has been known to affect the treatment rendered.

Aims: To evaluate the change in the attitude and expectations of the undergraduate dental students when introduced to a specially developed Geriatric Education Program (GEP) ii. To qualitatively analyse the students' perceptions and experience about the introduced GEP in their curriculum.

Materials and Methods: The study was conducted on II ${ }^{\text {nd }}$ year Bachelor of Dental Surgery students during the scheduled lectures of Prosthodontics. The study was conducted over a period of four and half years with the undergraduate students of IId $^{\text {nd }}$ Year $(\mathrm{n}=$ 206). In Stage one of the study, a structured GEP was developed with a multidisciplinary team based on Gerodontology and delivered to each batch of students of II ${ }^{\text {nd }}$ year Bachelor of Dental Surgery (BDS) over a period of four years. A questionnaire combining two standardized well accepted questionnaires - Expectations Regarding Aging (ERA-12) and Aging Semantic Differential (ASD-24) was developed. The students of each batch were given the questionnaire before and after the GEP and the changes in the attitude and expectations regarding aging were evaluated. In stage two of the study: A semi structured open-ended interview was conducted of the students to provide an in depth understanding of the experience, acceptance and perceptions of the introduced GEP. Transcripts were prepared and manual coding was done.
\end{abstract}

Statistical Analysis Used: The data so collected was subjected to statistical analysis using Student's paired t test and p values were evaluated. $p<0.05$ were defined as being statistically significant for the quantitative analysis. For the qualitative analysis, the thematic framework was prepared by analysing the data iteratively.

Results: A total of 206 students participated in the stage one of the study. The results showed a significant change in the attitude and expectation regarding aging, before and after the geriatric educational programme ( $p<0.05$, CI 95\%). The students felt that because of the programme added in their curriculum they have become more sensitive towards the aged, however, at the same time, they felt burdened by the addition of the program.

Conclusion: A structured educational intervention can bring about changes in the attitude and expectation of the dental students towards aging. Keeping the overall academic burden of the students in mind, educational interventions like geriatric education can be included in the dental curriculum at undergraduate level in India.

Keywords: Dental Education; Aged; Attitude; Geriatric Dentistry; Teaching 


\section{Introduction}

India has approximately, 59.8 million aged population (above 65 years), which is estimated to be equivalent to $5.0 \%$ of the total India's population as of January 2011 and around $10.8 \%$ of the world's above 65 years aged population [1]. This change in the demographics, offers challenges to the dental clinicians in treating the growing geriatric patients, especially now with the advancements of surgical procedures like dental implants. To meet these challenges, the training of young dental graduates requires greater efforts by the dental teaching institutes. Thus, in order to provide successful dental treatments to the geriatric patients, the dental undergraduates must receive a focused education in geriatric dentistry.

Although the Dental Council of India requires the dental students to develop communication skills, mental attitudes and diagnose geriatric patient, no separate educations methods in the form of lectures or training programs are delivered in this regard [2]. Highlighting this problem various researchers have emphasized on the need of including geriatric education in the dental curriculum in India [3-5]. Previous studies have shown that personal attitude towards age and older people correlates positively with the behaviour as well as the interest taken by the students in treating the older patients $[6,7]$. Successful treatments can be rendered if the students are trained to understand the needs, physiology, and psychology of the older patients. However, certain factors like the age difference (between the geriatric patients and undergraduate students), lack of contact with the aged in the family (due to increasing nuclear families), have been known to negatively influence the attitude of the students towards geriatric patients [8-12]. Thus, an early training with factual information about the elder can show an improvement in the attitude of the doctors [13]. Introducing special training programs aimed at aged population have been recommended. At the same time, it is essential to have an in-depth understanding of the effects of such extra added programs in the curriculum as well as how such programs are perceived by the students.

\section{Aim of the Study}

The aim of this mixed method study was to evaluate the change in the attitude and expectations of the undergraduate dental students when introduced to a specially developed GEP. An additional aim was to explore the students' experiences and perception of the GEP.

\section{Materials and Methods}

This mixed method research study used a Quantitative/Qualitative (Quan/Qual) explanatory two phase design. The study used a questionnaire (quantitative data) to analyse the change in attitude and expectations of the students towards the aged, while it used an interview method (qualitative data) to analyse the perception, acceptance and experience towards the newly added program in their curriculum. The study was approved by the ethical committee of the institution. (MGDCH/MDS/2017).

\section{Stage I}

The participants included in the study were all the enrolled students of the II ${ }^{\text {nd }}$ year BDS from the year 2015 - $2019(n=240)$. Thus, a convenient sampling method was used. The students were informed about the study and consent were obtained. Participants who were absent for any of the phase of the study, were excluded from the study. The study was divided into two phases.

Phase I: It involved assessing the needs and problems of the older patients and developing the GEP. A short self- structured survey was performed in the waiting area of the Department of Prosthodontics to assess the geriatric patient's concerns regarding dental care, general health, finances, transportation, caregiving, dependence $(n=20)$. These subjects merely helped in the development of the GEP and were not further involved in the study. The survey helped in developing the GEP based on the factual requirements and problems faced by the geriatric patients. The GEP was developed by senior faculty members of the Department of Prosthodontics and faculty of the medical college. The GEP consisted of a total of 8 lectures ( 1 hour duration each) spread over 8 weeks (Table 1). Each lecture consisted of a 45 min power point presentation followed by 15 minutes of group discussion. Senior teaching faculty of departments (who had ample clinical experience in handling and treating geriatric patients) conducted the lectures. The lecture series was made using standard textbooks and not just focused on the specific questions raised in the short survey. All the cohorts were exposed to the same lecture series, by the same faculty, to ensure standardization.

Phase II: It consisted of assessing the attitude and expectations of the students regarding aging, by means of a questionnaire. The se- 
Change in the Attitude and Expectations of Dental Students Regarding Aging by Introduction of a Geriatric Education Program: A Mixed Method Study

\begin{tabular}{|c|c|}
\hline Lecture & Topics covered \\
\hline Lecture 1 & $\begin{array}{l}\text { Introduction, Demographic shift in India, Life } \\
\text { expectancy, Quality of life of elderly in India, } \\
\text { Social and socio-economical aspects of aging in } \\
\text { India }\end{array}$ \\
\hline Lecture 2 & $\begin{array}{l}\text { Physiology of aging, Micro and macro } \\
\text { morphological age changes, Age changes in } \\
\text { bone physiology, Changes in taste, saliva, } \\
\text { mucous membrane. }\end{array}$ \\
\hline Lecture 3 & $\begin{array}{c}\text { Pharmacology in elderly, Hormone/ } \\
\text { Polymedication in elderly, Dementia and } \\
\text { neuropathic changes in elderly, Cognitive } \\
\text { impairment }\end{array}$ \\
\hline Lecture 4 & $\begin{array}{l}\text { Common systemic diseases in elderly in India, } \\
\text { Pathogenesis of age related diseases. }\end{array}$ \\
\hline Lecture 5 & Nutrition in elderly \\
\hline Lecture 6 & $\begin{array}{l}\text { Introduction to geriatric aspects in dental } \\
\text { treatments, Correlations between oral health } \\
\text { and systemic health }\end{array}$ \\
\hline Lecture 7 & $\begin{array}{l}\text { Brief introduction to dental problems like } \\
\text { periodontal diseases, root caries and root canal } \\
\text { treatment in elderly. }\end{array}$ \\
\hline Lecture 8 & $\begin{array}{l}\text { Communication skills - developing empathetic } \\
\text { communication with the elderlies. } \\
\text { Communication with elderly patients with } \\
\text { hearing and cognitive impairment. }\end{array}$ \\
\hline
\end{tabular}

Table 1: The structure of the geriatric education program.

lected subjects were given questionnaires which consisted of two parts: PART I- Demographic and social data about the participants. PART II- Consisted of 2 subsections: Subsection A: ERA-12 (Expectations Regarding Aging), it measured the respondent's expectations on a 5point Likert scale (strongly disagree, disagree, neutral, agree, strongly agree) [14]. Subsection B: ASD-24 (Aging Semantic Differential), it measured the respondent's attitude towards aging on a 5 point Likert scale (strongly disagree, disagree, neutral, agree, strongly agree) [15].

The participants were informed that the term "older person/ aged" referred to people 65 years and above, (as per WHO definition). However, this term also refers to people above 60 years of age (the nationally common retirement age in India). The participants were informed about the nature of the study and were advised not to be absent during the conduction of the GEP. A pre-GEP questionnaire was filled before starting the first lecture, while post-GEP questionnaire was filled by the participants after completion of the last scheduled lecture.

\section{Stage II}

The interviews sought to get an in-depth understanding of the experiences and how the students perceive extra added programs in their curriculum. A flexible schedule of the interview was used for the volunteering students for interview in each year. A semi structured open ended individual interview was designed. The interview was conducted by investigator PK and recording was done by BN. The interview questions were open ended with flexible sequence. These were: 1 . How did you like the introduction of an extra program in your curriculum? 2. Did you think you have benefitted from the program? In what way? 3. How do you think the program has brought about a change in you? 4. Do you think specialized programs like these can be added into the curriculum? 5. What was your experience like for this different program compared to your routine curriculum? All the interviews were audio recorded. Sampling was done till data saturation.

\section{Data collection and Statistical analysis}

Stage I: All questionnaires obtained were checked for completion and the general exclusion criteria. Out of a total 240 participants, 34 were absent during the conduction of the GEP questionnaire and were excluded. Thus, a total of 206 participants were evaluated. The data was transferred to Microsoft Excel by a single person and then converted to Statistical Package for the Social Sciences (SPSS) statistical software. The data so collected was subjected to statistical analysis using Student's paired t test and $\mathrm{p}$ values were evaluated. $\mathrm{p}<0.05$ were defined as being statistically significant.

Stage II: Data was transcribed and manual coding method was utilized to develop the themes. The transcriptions were read and re read to enhance the familiarization. Codes were developed and checked by an independent researcher. From the transcripts the sentences and phrases that were relevant to the qualitative aim of the study were identified and sorted into codes. In order to find relevant similarities and differences, repeated comparison and interpretation of the codes was done. Coding of the text was done independently by each of the researchers following which the codes were compared until agreement was reached. Thus, the themes and the codes were finalised. 
Change in the Attitude and Expectations of Dental Students Regarding Aging by Introduction of a Geriatric Education Program: A Mixed Method Study

\section{Results}

Out of a total 240 students, 34 were absent during the conduction of the GEP and thus were excluded. Out of a total of 206, 202 (98.1\%) participants belonged to the age group of 18 - 20 years, $170(82.5 \%)$ participants were females and 148 (71.8\%) participants lived without older people (Table 2).

\begin{tabular}{|l|c|c|}
\hline & Frequency (n) & Percent \\
\hline Age & & \\
\hline 18-20Years & 202 & 98.1 \\
\hline 21-25 Years & 4 & 1.9 \\
\hline Sex & 36 & 17.5 \\
\hline Male & 170 & 82.5 \\
\hline Female & 58 & 28.2 \\
\hline Living Condition & 148 & 71.8 \\
\hline With older people & & \\
\hline $\begin{array}{l}\text { Without older } \\
\text { people }\end{array}$ & & \\
\hline
\end{tabular}

Table 2: Descriptive data of the participants.
Cronbach's Alpha was 0.965 and 0.875 (36 items) of the Pre and Post GEP of the questionnaire, which signified high level of internal consistency of our scale.

A statistically significant difference in expectations regarding the aged, before and after the GEP was noted ( $<<0.05) .7$ out of the 12 items of subsection A, showed a significant difference $(\mathrm{p}<0.05$ and CI of 95\%). Expectations regarding physical health showed most change ( 3 out of 4 items) while in both cognitive function and mental health, 2 out of 4 items showed statistically significant difference (Table 3).

Out of the 24 items in subsection B, 15 items showed a statistically significant difference ( $p<0.05$, at CI 95\%). In the current study, out of the four factor solution provided, the maximum impact of the GEP was seen on autonomy ( 6 out of 8 items showed statistically significant difference post GEP) while minimum impact was shown on instrumentality (2 out of 5) (Table 4).

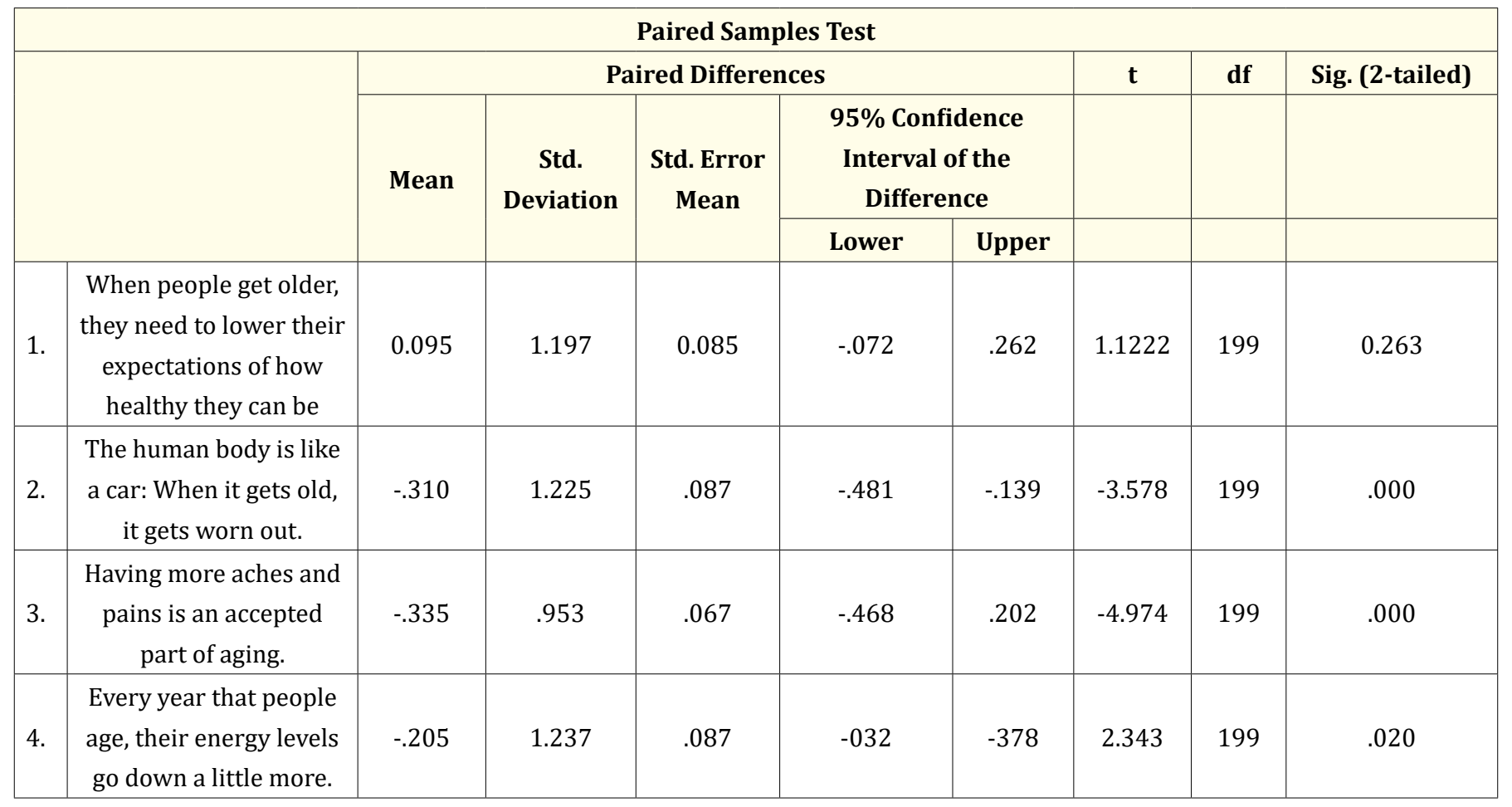


Change in the Attitude and Expectations of Dental Students Regarding Aging by Introduction of a Geriatric Education Program: A Mixed Method Study

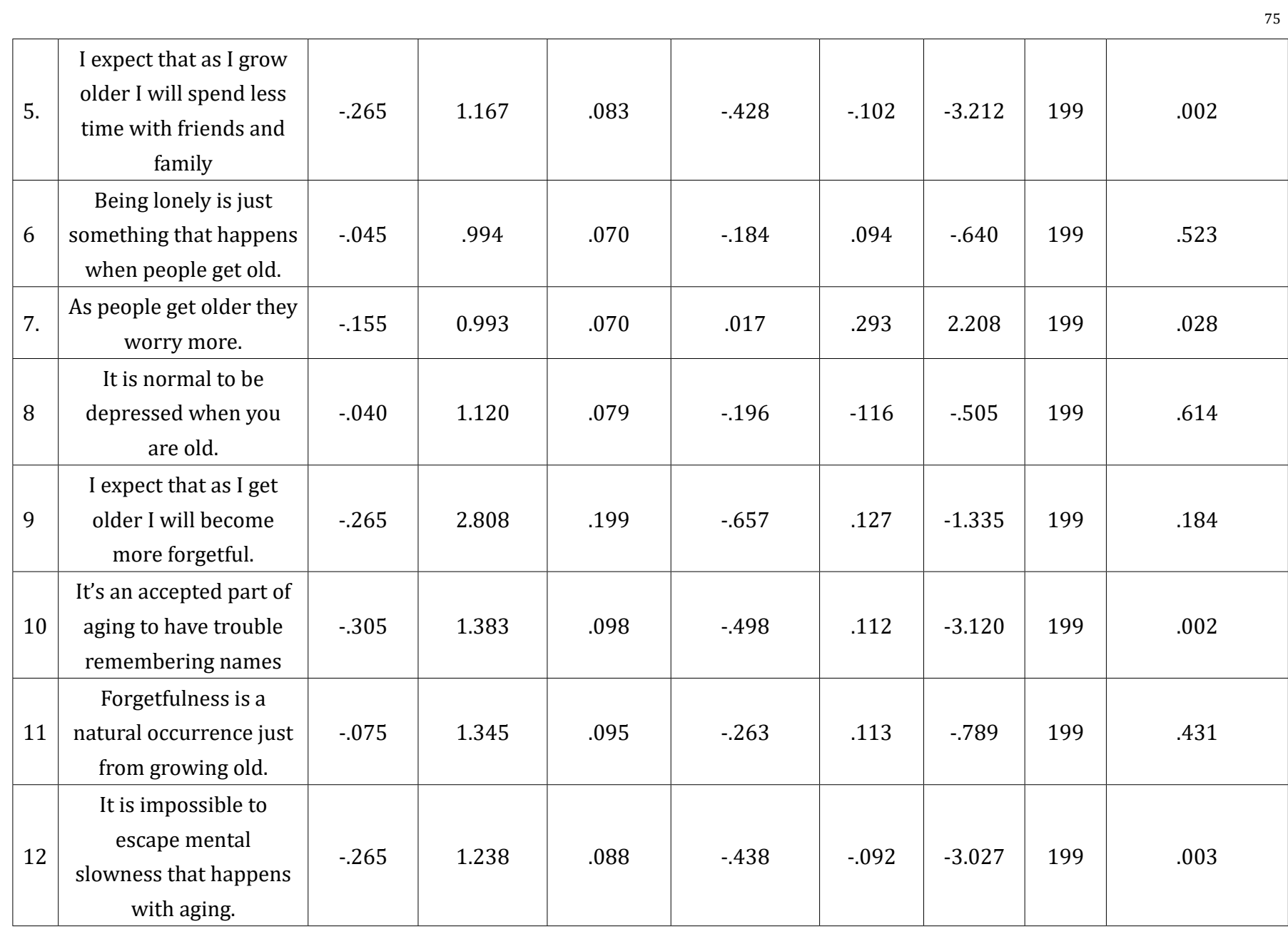

Table 3: Results of section A of the questionnaire.

By the twenty second student data saturation was achieved. The thematic framework after the content analysis was prepared (Table 5). When asked how did they think the program benefitted them the students felt they have a better understanding of the aged, they have become understanding towards the elderly.

I felt I can relate to elders of my house better after the program. I have a better understanding of aging process and the physiology. The social aspects of elderly in India that were covered has made me sympathetic towards them (Interview 3).

I think I can handle an elderly patient better in the clinical posting next year. I have understood to be more empathetic and understanding towards elderly (Interview 10).
It was clear from the program, it is important to communicate with the caretakers of the elderly during clinical appointments. As our routine curriculum does not give a thorough understanding of special age groups, I feel this program is important. Specially for Prosthodontics denture making (Interview 5).

Regarding addition of such programs in the curriculum, it was evident that students felt it could burden their schedules.

The program was good, but too long. So many lectures starts getting taxing (Interview 6).

Adding such programs is important but it should be added in sync with our regular course. Adding more and more programs will put us under a lot of pressure (Interview 7). 
Change in the Attitude and Expectations of Dental Students Regarding Aging by Introduction of a Geriatric Education Program: A Mixed Method Study

76

\begin{tabular}{|c|c|c|c|c|c|c|c|c|c|}
\hline \multicolumn{10}{|c|}{ Paired Samples Test } \\
\hline & & \multirow{2}{*}{ Mean } & \multirow{2}{*}{ Std. Deviation } & \multirow{2}{*}{$\begin{array}{c}\text { Std. Error } \\
\text { Mean }\end{array}$} & \multicolumn{2}{|c|}{$95 \%$ Confidence Interval of the Difference } & \multirow[t]{2}{*}{$\mathbf{t}$} & \multirow[t]{2}{*}{ df } & \multirow{2}{*}{$\begin{array}{c}\text { Sig. } \\
\text { (2-tailed) }\end{array}$} \\
\hline & & & & & Lower & Upper & & & \\
\hline 1 & Active-Inactive & -.095 & 1.096 & .078 & -.248 & .058 & -1.225 & 199 & .222 \\
\hline 4 & Selfish-Unselfish & -.190 & .817 & .058 & -.304 & -.076 & -3.289 & 199 & .001 \\
\hline 5 & Idle-Occupied & -.090 & 1.277 & .090 & -.268 & .088 & -.997 & 199 & .320 \\
\hline 6 & Secure-Insecure & -.226 & 1.461 & .104 & -.430 & -.022 & -2.183 & 198 & .030 \\
\hline 7 & Strong-Weak & -.345 & 1.101 & .078 & -.499 & -.191 & -4.432 & 199 & .000 \\
\hline 11 & Decisive-Indecisive & -.230 & 1.088 & .077 & -.382 & -.078 & -2.991 & 199 & .003 \\
\hline 12 & Happy-Sad & -.060 & .991 & .070 & -.198 & .078 & -.857 & 199 & .393 \\
\hline 13 & Tidy-Untidy & .005 & .830 & .059 & -.111 & .121 & .085 & 199 & .932 \\
\hline 14 & Tolerant-Intolerant & -.280 & 1.144 & .081 & -.439 & -.121 & -3.462 & 199 & .001 \\
\hline 15 & Dull-Exciting & -.260 & 1.170 & .083 & -.423 & -.097 & -3.142 & 199 & .002 \\
\hline 16 & Handsome/beautiful-Ugly & -.095 & 1.086 & 0.078 & -.248 & .058 & -1.225 & 199 & 0.22 \\
\hline 17 & Friendly-Unfriendly & -.040 & 1.096 & .078 & -.193 & .113 & -.518 & 198 & .605 \\
\hline 18 & Productive-Unproductive & -.231 & 1.088 & .077 & -.382 & -.078 & -2.991 & 199 & .003 \\
\hline 24 & Ordinary-Special & -095 & 1.096 & .078 & -.248 & .058 & -1.225 & 199 & .222 \\
\hline
\end{tabular}

Table 4: Results of section B of the questionnaire.

When asked about the experience the students had with the introduction of the program, it emerged that using a focused topic of discussion, group discussions and different faculties helped the students (Table 5).

\section{Discussion}

The current study used a mixed study method, the use of quantitative and qualitative data is used as it explains complementary aspects of the same phenomena. A mixed method of study gave a deeper and broader understanding of an educational intervention in the form of GEP.

It is known that attitude of the clinician influences the treatments rendered [5]. However, studies have shown that the attitude of nursing, medical and the dental hygiene students is not very suitable towards the older patients $[5,8,17]$. Thus, greater efforts for an overall improvement in the attitude of the health care providers towards older patients is suggested. It has been shown previously 
Change in the Attitude and Expectations of Dental Students Regarding Aging by Introduction of a Geriatric Education Program: A Mixed Method Study

\begin{tabular}{|c|c|c|}
\hline Bene & Uuition & \\
\hline $\begin{array}{l}\text { I think it helped me the most by } \\
\text { increasing empathy towards aged, not } \\
\text { just my grandparents but aged people in } \\
\text { general. (Interview 7). } \\
\text { I understood most of the things taught } \\
\text { in the program and I feel I can } \\
\text { understand the psychology of the elderly } \\
\text { better now (Interview 6). }\end{array}$ & $\begin{array}{c}\text { The program was good, but too long. So many } \\
\text { lectures starts getting taxing. (Interview 6). } \\
\text { We will definitely benefit from these programs, } \\
\text { but I hope there are no exams on it, studying so } \\
\text { many subjects will be very difficult for us. } \\
\text { (Interview 10). }\end{array}$ & $\begin{array}{l}\text { I know other colleges do not have something like } \\
\text { that in their college. These extra teaching and } \\
\text { with no exams on it doesn't help. (Interview 18). } \\
\text { The program had many lectures by different } \\
\text { faculty and I think if this is not in our syllabus } \\
\text { then why do it? (Interview 2). }\end{array}$ \\
\hline $\begin{array}{l}\text { Better handling of elderly patients in } \\
\text { the clinics. } \\
\text { I do have grandparents at home, but } \\
\text { learning more about this age group } \\
\text { in the class will definitely help me to } \\
\text { handle patients better in the clinics. } \\
\text { (Interview 11). } \\
\text { I am most worried about other medical } \\
\text { conditions that elderly have which may } \\
\text { affect our handling. After this program } \\
\text { I think...I feel I am more confident in } \\
\text { understanding all medical conditions } \\
\text { that I may see in patients in the clinics. } \\
\text { (Interview 19). }\end{array}$ & $\begin{array}{l}\text { The course will clash with our ongoing curricu- } \\
\text { lum. } \\
\text { The course was too long. The practical classes } \\
\text { and the theory lectures schedule did not match. If } \\
\text { it is added, extra lectures must be taken... } \\
\text { otherwise the routine syllabus will not get } \\
\text { covered. (Interview 16). }\end{array}$ & $\begin{array}{l}\text { Group discussions and learning from different } \\
\text { faculty was useful. } \\
\text { I thoroughly enjoyed the group discussions. } \\
\text { Discussing and talking with others helped in } \\
\text { clearer understanding. Our routine lectures do } \\
\text { not have group discussions so it was different. } \\
\text { (Interview 11). } \\
\text { The discussions the teachers took in the end } \\
\text { were very interesting. It made me understand } \\
\text { the topic better. Somethings I wouldn't } \\
\text { understand through the lecture would get clear } \\
\text { in the discussion. Also there were different } \\
\text { teachers of different departments teaching....it } \\
\text { made it good. (Interview 2). }\end{array}$ \\
\hline $\begin{array}{l}\text { Drawing attention towards the aged. } \\
\text { We all know that there are aged people } \\
\text { around, but we don't give them special } \\
\text { attention. After this program, I think I } \\
\text { will pay more attention to them...like... } \\
\text { notice them more. (Interview 9). }\end{array}$ & $\begin{array}{l}\text { Examination on the course. } \\
\text { If there is no examination on the course in the } \\
\text { end...we will not take it seriously. So, if it has to } \\
\text { be added in the curriculum there must be a test } \\
\text { at the end. (Interview 16). } \\
\text { It is easy to keep adding extra courses but with } \\
\text { exams or without exams that is a bigger issue. If } \\
\text { it is without exams.. studying wont be too much } \\
\text {, if it is with exams then there will be too many } \\
\text { exams we have to give. (Interview 9). }\end{array}$ & $\begin{array}{l}\text { Increased knowledge in a focused area. } \\
\text { The entire program was on one topic- elderly. } \\
\text { and all aspects were covered on elderly. This is a } \\
\text { good way of learning. Taking one focused topic } \\
\text { and discussing all aspects of it. (Interview 17). } \\
\text { It is was a bit different from our routine } \\
\text { curriculum as we were taught about one topic } \\
\text { clearer understanding of elderly. (Interview 14). }\end{array}$ \\
\hline
\end{tabular}

Table 5: Excerpts from participant interviews.

Citation: Pragati Kaurani., et al. "Change in the Attitude and Expectations of Dental Students Regarding Aging by Introduction of a Geriatric Education Program: A Mixed Method Study". Acta Scientific Dental Sciences 5.5 (2021): 71-80. 
that improved educational methods leads to better competence and enhanced attitude towards patients resulting in better professional therapy and conduct $[17,18]$. Thus, education can be used as a tool to improve the attitude of dental students helping them to get trained to provide improved treatments to the patients. This becomes particularly important for certain sections of the society like the older people.

206 dental students participated in the questionnaire, over a period of 4 years with a response rate of $85 \%$. Most of the students were in the age group of 18 - 20 years at the pre-clinical training stage (98.1\%) and lived without elders (71.8\%). This highlights the age difference that exists between the students and the geriatric patients as well as the lack of exposure with older people. Both of these factors have been shown to have the potential to affect the health care delivery $[8,19]$. While majority of the students were females, our study did not evaluate the influence of gender attitude and expectations towards the aged. Though, there is evidence to suggest the effect of gender on the general attitudes towards older people [9]. This needs further evaluation in relation to Indian dental students.

Out of the three factors stated by Tews that affect development of age images (knowledge, attitude and one's own expectations of aging), the current study used two (knowledge and expectations), both showing significant changes after the GEP [20]. Our results are similar to Border and Block, who found significant improvement after a geriatrics course [21].

The change in the expectations in the current study, was evaluated using ERA 12 which measures expectations regarding aging using three item subscale - expectations regarding cognitive function, mental health and physical health [22]. The concept of ERA has been stated as expecting maintenance and achievement of high level of mental and physical functioning with ageing, this indicates the expectation of healthy ageing for other people and self [22]. These perceptions of aging has been thought to influence the health outcomes [14]. The changes in the current study were significant in the subscales of autonomy, physical health and cognitive health. Attitude towards the aged has been defined as the beliefs and the feelings that one has towards the aged [24]. In the current study, the meaning of attitude was to get to understand the dental students' predispositions and tendencies towards the aged. Originally developed by Roseneranz and McNevin attitude was tested using ASD which is a 32 item scale which was later modified [24]. Polizzi in 2003, showed ASD 24 has a four factor solution - acceptability, integrity, autonomy, instrumentality [15]. Acceptability refers to the extent to which one is at ease socially, instrumentality refers to the active pursuit of goals, autonomy refers to being self-sufficient and integrity refers to being at peace with oneself. In the current study, out of the four factor solution provided, the maximum impact of the GEP was seen on autonomy while minimum impact was shown on instrumentality [25]. These results are partially similar to the results obtained by Nochajski [9]. This may be attributed to the similar educational intervention in both the studies.

It is not be possible to confirm that changes in attitudes was entirely due to the introduced GEP, however, as majority of the students were in hostels, the possibility of any other sudden influencing factor is minimum. We, however, did not include knowledge as a variable in the questionnaire. Knowledge is measured by FAQ and it measures the general knowledge of aging, which we believe would not have changed after the GEP. The GEP covered academic topics on ageing and would have no effect on the general knowledge of subject. It was thus decided to exclude FAQ II.

Gerodontology aims to create awareness of attitude, knowledge and skills to handle oral health care of geriatric patients [28]. It deals with health issues concerning the aged that are inter and multidisciplinary and closely related to subjects in the medical field [9].Thus, it is an additional subject with close links to general medicine. The GEP was structured following the guidelines given by Kossini [27]. All relevant topics were systematically covered using the standard textbooks available on geriatrics. The students chosen were II $^{\text {nd }}$ year dental undergraduates, as they would have the basic knowledge of anatomy and physiology making it easier for them to understand the lecture series. At the same time, as they would have had no clinical exposure to older patients, thereby, eliminating the effects of their individual clinical experiences on the results which has been shown to change in the attitude $[9,12]$.

Various Indian researchers have previously emphasized that Gerodontology should be included in preclinical, clinical subjects at undergraduate level [2-4,26]. Although few colleges have special geriatric dental clinic, however, dedicated lecture and training to deal with the physical, social and psychological issues dealing with the older patients is not under taken. However, various other 
countries have realized the significance of Gerodontology and have introduced it in the curriculum. In most of the Swizz universities, Gerodontology is well established and have well established geriatric teaching in lectures and practicals [7]. Countries like England, USA and Scandinavia have Special Care Dentistry [28]. In 2004, The Association for Dental Education formed the "The profile and the competences for the European Dentist" and extended it with particular relevance to care of older patients [29].

Though addition of such programs is essential, it was evident from the interviews obtained that care must be taken to structure such programs so as not to burden the students. The study showed that the students well accepted the program however, were concerned about extra added lectures in their curriculum. Thus, the introduction of added programs must be well thought by the academic authorities.

R Samra have found geriatric education to have a poor relation to the attitudes of medical students towards older patients and questions the assumption of effects of early exposures [30]. The reported review, however, had no study conducted on Indian students. Thus, the results may not be applicable on Indian students. In India, dental education is still primarily taught by conventional didactic lectures and keeping the same pattern of education, it was decided to conduct the GEP in the lecture format. Keeping the teaching method similar to what the students are familiar with might have helped the students in easy understanding the of topics covered.

\section{Limitations of the Study}

Even though a well-structured GEP was executed in the form of lectures, the study lacked a practical phase like a visit to a geriatric ward or an old age home. Exposure and interaction with the elderlies through such phases may further change the attitude of the students. Future studies must consider how educational intervention and change in the attitude influences subsequent behaviour of students towards older patients in the clinics.

\section{Conclusion}

The study proves the effectiveness of a structured educational intervention in changing the attitude and expectations of second year dental students regarding aging. The experience of the students regarding the program showed that they felt the program helped them by making them more sensitive towards the aged, however, they felt burdened due to addition of program in their curriculum.

\section{Acknowledgement}

We would like to acknowledge, Dr Narendra Padiyar, Principal, Prof and Head, Mahatma Gandhi Dental College and Hospital, without whose support this study would not have been possible. Dr Padiyar helped in accommodating the GEP in the routine time table of the undergraduate students as well as in the smooth execution of the study.

\section{Bibliography}

1. Mishra V. “India's Projected Aged Population (65+), Projected Life Expectancy at Birth and Insecurities Faced by Aged Population". Ageing International 45 (2020): 72-84.

2. Dental Council of India, BDS Course Regulations (2007).

3. Shah N. "Need for gerodontology education in India". Gerodontology 22 (2005): 104-105.

4. Patil P., et al. "Influence of early clinical exposure for undergraduate students on self -perception of different aspects of geriatric dental care: Pilot study between two colleges from Japan and India". The Journal of the Indian Prosthodontic Society 16.3 (2016): 288-293.

5. Talwar M and Chawla H. "Geriatric dentistry: Is rethinking still required to begin undergraduate education?" Indian Journal of Dental Research 19 (2008): 175-177.

6. Anehosur G and Nadiger RK. "Evaluation of understanding levels of Indian dental students' knowledge and perceptions regarding older adults". Gerodontology 29.2 (2012): e12151221.

7. Wiese CH., et al. "Geriatrics in medical students' curricula: questionnaire-based analysis". BMC Research Notes 7.1 (2014): 472.

8. Klaghofer R., et al. "Attitudes toward older people at the beginning and end of medical students' education". Zeitschrift fur Gerontologie und Geriatrie 42.5 (2009): 365-371.

9. Weiner R., et al. "Dental hygiene students' perceptions of older adults". Journal of Dental Education 78.12 (2014): 1623-1628. 
10. Nochajski T., et al. "Factors that influence dental students' attitudes about older adults". Journal of Dental Education 73.1 (2009): 95-104.

11. Happell B. "Nursing home employment for nursing students: valuable experience or harsh deterrent?" Journal of Advanced Nursing 39.6 (2002): 529-536.

12. McKinlay A and Cowan S. "Student nurses' attitudes towards working with older patients". Journal of Advanced Nursing 43.3 (2003): 298-309.

13. Fabiano JA., et al. "Understanding dental students' knowledge and perceptions of older people: Toward a new model of Geriatric Dental Education". Journal of Dental Education 69.4 (2005): 419-433.

14. Sarkisian CA., et al. "Development of the 12-Item Expectations Regarding Aging Survey”. Gerontologist 45.2 (2005): 240-248.

15. Polizzi K. "Assessing attitudes toward the elderly: Polizzi's refined version of the aging semantic differential". Educational Gerodontology 29.3 (2011): 197-216.

16. Nochajski TH., et al. "Factors that influence dental students' attitudes about older adults". Journal of Dental Education 73.1 (2009): 95-104.

17. Celik S., et al. "Views and attitudes of nursing students towards ageing and older patients". The Australian Journal of Advanced Nursing: AJAN 27.4 (2010): 24-30.

18. Goldenhar LM and Kues JR. "Effectiveness of geriatric medical student's scholars program: a qualitative assessment". Journal of the American Geriatrics Society 54.3 (2006): 527-534.

19. Grundy E and Read S. "Social contacts and receipt of help among older people in England: are there benefits of having more children?" The Journals of Gerontology, Series B: Psychological Sciences and Social Sciences 67.6 (2012): 742-754.

20. Tews HP. "Images of aging”. In Kuratorium Deutsche Altershilfe (public KDA) 16 (1991): 152.

21. Border H and Block MJ. "Effects of geriatric education on the knowledge of dental students". Special Care in Dentistry 6.4 (1986): 177-179.

22. Joshi VD., et al. "Validity and reliability of the expectations regarding aging (ERA-12) instrument among middle -aged
Singaporeans". ANNALS Academy of Medicine Singapore 39.5 (2010): 394-398.

23. Divilova S. "Semantic differential as one of the research tools suitable for establishing the attitudes of pupils to old age and seniors". Universal Journal of Educational Research 4.8 (2016): 1858-1862.

24. Rosecranz Tony E., et al. "A factor analysis of attitudes towards aged". Gerontologist 9.1 (1969): 55-59.

25. Brooks T. "Attitudes of medical students and family practice residents toward geriatric patients". Journal of the National Medical Association 85.1 (1993): 61-64.

26. Bharti R., et al. "Oral care needs, barriers and challenges among elderly in India". The Journal of the Indian Prosthodontic Society 15.1 (2015): 17-22.

27. Kossioni A., et al. "European College of Gerodontology: undergraduate curriculum guidelines in Gerodontology". Gerodontology 26.3 (2009): 165-171.

28. Stronger RL., et al. "Reflections on changes in geriatric dentistry”. Journal of Dental Education 64.10 (2000): 715-722.

29. Plasshaert AJ., et al. "Profile and competences for European Dentist". European Journal of Dental Education 9.3 (2005): 98107.

30. Samra R., et al. "Factors related to medical students' and doctors' attitudes towards older patients: a systematic review". Age Ageing 46.6 (2017): 911-919.

\section{Assets from publication with us}

- Prompt Acknowledgement after receiving the article

- Thorough Double blinded peer review

- Rapid Publication

- Issue of Publication Certificate

- High visibility of your Published work

Website: www.actascientific.com/

Submit Article: www.actascientific.com/submission.php

Email us: editor@actascientific.com

Contact us: +919182824667 